\title{
Access and Intensity of Mechanization: Empirical Evidence of Rice Farmers in Southern Ghana
}

\author{
John K. M. Kuwornu ${ }^{1}$, Emmanuel K. Apiors ${ }^{2}$, George T-M Kwadzo ${ }^{3}$. \\ ${ }^{1}$ Asian Institute of Technology, Department of Food, Agriculture and Bioresources, Thailand; ${ }^{2}$ University of Ghana, \\ Department of Agricultural Economics and Agribusiness, Legon, Accra, Ghana; ${ }^{3}$ Ministry of Food and Agriculture, \\ Accra, Ghana.
}

\begin{abstract}
The medium term development plan of Ghana proposed modernization of agriculture to lead the way in transforming the economy. Providing irrigation infrastructure and enhancing farmer access to farm machinery were major interventions proposed. In line with this, the government has been investing in irrigation infrastructure as well as importing farm machinery under various programmes in recent years.

This study analyzed access and intensity of mechanization by rice farmers in southern Ghana. The Shai-Osudoku and Ketu North Districts were purposively selected and a total of 360 farmers were randomly sampled from 16 rice growing communities. In general, the results of the descriptive statistics revealed that about $74 \%$ of farmers were still cultivating rice with considerably low level of mechanization. The double hurdle model was employed to estimate the determinants of access to mechanization and the intensity of mechanization. The empirical results of tier one of the double huddle model revealed that size of land, access to credit, availability of farm machinery, expenditure on labour, agrochemical expenditure, the square of age, and gender positively influenced access to mechanization. Seed expenditure, age and district locations negatively influenced access to mechanization. The empirical results of the tier two of the double hurdle model revealed that distance from farm to nearest mechanization centre, rice income, non-farm income and experience were significant variables that positively influenced intensity of mechanization. Land ownership and household size negatively influenced intensity of mechanization. These results have implications for capacity building and government support for rice farmers in southern Ghana.
\end{abstract}

Key words: mechanization access, mechanization intensity, rice farmers, southern Ghana, double hurdle model

\footnotetext{
*Author for correspondence: jkuwornu@gmail.com
} 


\section{INTRODUCTION}

The medium-term development plan of Ghana, Growth and Poverty Reduction Strategy (GPRS II) indicates clearly its expectation of the Agriculture sector to spearhead growth and structural transformation of the Ghanaian economy ${ }^{[1,2]}$. It further notes that due to the high incidence of poverty in the sector, benefit of accelerated growth would be maximized when agriculture modernization is pursued. Improving access to mechanized agriculture and accelerating provision of irrigation infrastructure are two major interventions proposed among others for modernizing agriculture ${ }^{[3]}$.

Mechanization of rice production is a major objective of the Medium-Term Agricultural Sector Investment Plan (METASIP). The proposed intervention is to provide assistance to Private Sector to set-up commercially viable Agricultural Mechanization Services Enterprise Centers (planters, combine harvesters, etc) at strategic locations ${ }^{[3]}$. This will increase rice farmers' access to machinery, improve their productivity; improve the capacity of local rice industry to compete with imported rice. Efficient use of labour and inputs, timeliness of operations and promoting sustainable systems are the primary methods of productivity enhancement in rice production ${ }^{[4]}$.

In response to food security and emergency preparedness, targeted investment in mechanization from 2011-2015 was GHS 100 million, placing it second to investment expenditure in irrigation ${ }^{[5]}$. The Government of Ghana evaluated a largescale commercial irrigation project known as the 'Accra Plains Irrigation Development Project' aimed at developing land covering the Accra Plains for farming using water from River Volta ${ }^{[6]}$.

This project, if realized, will have an area twenty times greater than the entire current public/state irrigated area in the country. The project will accommodate about 10,000 modernized irrigation farms (based on a minimum of 20 ha per farm) with a capacity to give employment to about 100,000 people.

From the year 2000 to 2010, the Government of Ghana under the Japanese Grant Assistance, 2KR-programme, imported a number of agricultural machinery yearly to enable farmers' access to modernized agriculture ${ }^{[7]}$. These include tractors, tractor matching implements, water pumps, slashers, power tillers, irrigation pumps and accessories, rice reapers, rice threshers, rice combine harvesters and rice mills.

Numerous studies argue that the problem of low agricultural productivity in SubSaharan Africa is due to poor levels of mechanization rather than technical inefficiency ${ }^{[8-11]}$. This suggests that adoption levels of labour-saving technologies are rather declining. Moreover, experience from some African countries including Ghana, established that policy reforms on mechanization have failed due to lack of economic demand from farmers and fiscal burden of state-sponsored programs ${ }^{[12-17]}$. The major Ghana agriculture sector policy provision, for instance Agricultural Sub Sector Improvement Programme (AgSSIP) and Food and Agriculture Sector Development Programme (FASDEP) initiated steps to address the low productivity problem by funding agricultural mechanization ${ }^{[18]}$.

Available data on rice productivity in Ghana revealed that between 2002 and 2010 average yield of rice was $1.7-2.4 \mathrm{Mt} / \mathrm{Ha}$ compared with achievable yield of $6.5 \mathrm{Mt} / \mathrm{Ha}$ ${ }^{[7]}$. This indicates that the yields are far below the achievable yield. Therefore, to what extent has the importation of the mechanization equipment improved access of rice farmers to mechanized services? Are the services available to farmers and for which activities? What proportions of farmers are able to access these services? What factors influenced the farmers' access and intensity of mechanization. Answers to these questions necessitate this current study. Therefore, the objectives of this study were fourfold. First, the study identified the sources of mechanization services

Braz. Arch. Biol. Technol. v.60: e17160396 Jan/Dec 2017 
accessed by rice farms. Second, the study assessed the level of mechanization access achieved by rice farmers. Third, it examined the determinants of access to mechanization by farmers. Fourth, the study examined the determinants of intensity of mechanization on rice farms.

This study provides evidence on the extent to which machinery importation improved rice farmers' access to mechanised inputs, indicating the effectiveness of policy interventions on agricultural mechanization. This provides a guide to policy makers in choosing interventions that will improve modernisation of agriculture in the future. Also, evidence on the level of activity mechanization will inform the public, private service providers and policy makers on the extent of activity mechanization on rice farms. Private businessmen will be informed about services to invest in and where to locate mechanization service centers strategically, for easy access and use by farmers. The study also provides information about the intensity of mechanization on rice farms.

\section{MATERIALS AND METHODS}

\section{THE STUDY AREA, SAMPLING AND DATA}

The study covered two major rice growing districts in Southern Ghana, communities in and around Asutsuare in the Shai-Osudoku District in the Greater Accra Region, and communities in and around Weta in the Ketu North District in the Volta Region of Ghana. Asutsuare has about 2786 hectares of land under cultivation while Weta has about 880 hectares of land under rice cultivation. These districts were selected because government through the Irrigations Development authority (IDA) has made substantial investment in developing irrigation infrastructure in these areas for rice production. Based on the farmer population in the respective districts, 254 farmers from Asutsuare area and 106 farmers from Weta area were interviewed, to give a total sample size of 360 farmers. Secondary data included rice development policies and schemes, rice productivity levels from MoFA, irrigation development policies from IDA, rice trade policies from Ministry of Trade and Industry, and population of the study communities from the Ghana statistical service. The rice growing communities were selected purposively and respondents were randomly selected within each community. Cross-sectional data for the 2012 major season at farm level were solicited from rice farmers using structured questionnaires.

\section{SOURCES OF MECHANIZATION SERVICES ACCESSED BY FARMERS}

Farmers were asked to identify sources of mechanization whether farmer owned, private service providers, or Government mechanization centers. Descriptive statistics was used to describe the sources of access to mechanization.

\section{LEVEL OF MECHANIZATION ACCESSED BY FARMERS}

All the possible production activities from land preparation through to harvesting were listed and presented to the farmer. The procedure used by ${ }^{[19]}$ was adopted for analysis. An index based on farmers ownership pattern and use of modern rice cultivating implements like power tiller, planters, sprayers, and harvesters, for respective activities was used. The farmers' response to the use of these implements was coded into scores, 1 for ownership or hired usage of implement for an activity, and 0 otherwise. The total score calculated ranged from $0 \%$ to $100 \%$ depending on the number of production activities for which mechanization was used in 2012 major season of production. If a farmer had a total calculated score of $50 \%$ and above then it means half or more of his/her production activities was based on mechanization 
and a value of 1 is assigned to the farmer and 0 otherwise. Descriptive statistics was used to describe the levels observed.

\section{ECONOMETRIC SPECIFICATION OF THE DOUBLE HUDDLE MODEL}

The decision to mechanize a farm and the number of activities to mechanize in a farms' production cycle can be made jointly or separately. In a situation where the two decisions are affected by the same set of explanatory variables, the double huddle model is equal to the Tobit model ${ }^{[20]}$. In other words, the use of the Tobit model is based on the assumption that the same sets of factors influence the decision to mechanize and the scope of use of mechanization.

The double hurdle model defines an initial discrete probability of access to mechanization and secondly, a decision on the intensity of mechanization. The twotier model relaxes the assumptions and enables separate mechanism to dictate the probability of a farmer mechanizing rice farm and the intensity of activity mechanization ${ }^{221,22]}$. The double hurdle model has an access to mechanization equation given by:

$$
\left\{\begin{array}{l}
M_{i}=1 \quad \text { if } M_{i}^{*}>0 \\
M_{i}=0 \quad \text { otherwise } \\
M_{I}^{*}=\alpha^{\prime} Z_{I}+u_{i}
\end{array}\right\}
$$

Where $M^{*}$ is a latent variable that takes the value 1 if a farmer achieved whole farm mechanization and 0 otherwise. $Z$ is a vector of household characteristics, $\alpha$ is a vector of production parameters and $\mu$ is the disturbance term.

Access and intensity of mechanization

The intensity of mechanization $\mathrm{Y}$ is given as:

$Y_{i}=\left\{\begin{array}{c}y^{*}=\beta^{\prime} X_{I}+v_{i} \\ 0 \quad \text { otherwise }\end{array}\right.$ if $y^{*}>0$ and $M^{*}>0$

Where $\mathrm{X}$ is a vector of socio economic characteristics of the farmer and $\beta$ is a vector of parameters. The error terms are $\mu_{i}$ and $v_{i}$. The assumption is that the error terms $\mu_{i}$ and $v_{i}$ are independent as proposed by ${ }^{[21]}$. For the purposes of this study, the double huddle model used by ${ }^{[11]}$ is adopted.

$$
\begin{aligned}
& P\left(Y_{1}-1\right)-P\left(Q^{*}>0\right)-X_{1} \alpha+\varepsilon_{(\text {Mechanization access model) (3) }} \\
& Q^{*}=Z_{1} \beta+\mu \quad \text { (Intensity of mechanization model) }
\end{aligned}
$$

Equation (3) defines access to mechanization model and equation (4) defines the intensity of mechanization model. Y takes on the value of 1, if 6 or more activities on the farm were mechanized and 0 otherwise. $Q^{*}$ is the observed proportions of activities mechanized. $X_{l}$ define set of variables that determined discrete probability of mechanization access (land, credit access, membership of farmers based organisation, availability of machinery, improved seed, labour, fertilizer, agrochemicals, age, square of age, gender, and district). $Z_{l}$ define set of variables 
that determined intensity of mechanization (land, land ownership, labour, distance to mechanization centre, credit amount, rice income non-farm income, extension, age, gender, experience, household size).

\section{DESCRIPTION AND MEASUREMENT OF VARIABLES OF ACCESS TO MECHANIZATION}

Land: This variable represents farm size measured in hectares. Larger cultivated areas will cause a farmer to invest in mechanization as compared to smaller cultivated areas ${ }^{[11]}$. It is hypothesized that with efficient management practices, larger land sizes increase yield per area and hence income.

Labour: This variable indicates labour expenditure measured in GHS. The amount of labour available could influence access to mechanization. Skilled labour is required to operate farm machinery. Research suggests that increased mechanization is associated with increase in labour expenditure ${ }^{[23]}$. It is hypothesized that increase in labour expenditure is positively related to access to mechanization.

Credit: This variable represents access to institutional credit (dummy). One is scored for farmers who had access to credit and zero otherwise. Access to institutional credit increases a farmer's financial capability to purchase modern farm equipment or hire mechanized services from service providers ${ }^{[15]}$.

Membership of farmer based organisation: This variable indicates membership of farmer based organisation. This is a dummy variable, 1 for when a farmer is a member of any farmer based organisation and zero otherwise. It is hypothesized being part of a farmer based organisation is positively related to access to mechanization as a result of cooperative power of acquiring farming inputs.

Availability of mechanization service: This is availability of mechanization service centre or equipment in the community measured as a dummy variable. One is scored for farmers who had access to mechanization and zero otherwise. Accessing mechanized service depends on its availability. Farmers in communities with available mechanical service centres, for instance, harvesters are more likely to employ it in their harvesting activity. But absence of mechanized service centres in the community will cause farmers to employ more labour for an activity.

Seed: Expenditure (GHS) on improved seed used. High yielding varieties are mostly improved and will require a farmer to purchase since it is produced by certified seed dealers. These seeds may require precision in planting distance and other cultural practices which favours farmer's decision to mechanize ${ }^{[19]}$.

Fertilizer: This is fertilizer use intensity estimated in monetary value (GHS). Fertilizer usage compliments intensification of mechanization ${ }^{[24]}$. Use of adequate quantities of appropriate fertilizer is expected to be positively related to mechanization ${ }^{[15]}$.

Agrochemical: This is expenditure on combined use of weedicide, insecticide fungicides, and other agrochemicals used. This is expected to be positively related farm mechanization access. Mechanization of farms is associated with increases usage of agrochemicals ${ }^{[19]}$.

Age: This is the age of farmer in years. Older farmers are likely to have saved enough as compared to younger farmers, hence, making older farmers more able to afford investment in mechanization equipment ${ }^{[19]}$.

Gender: This is gender of farmer measured by a dummy. One is scored for male farmers and zero otherwise. The effect of gender on mechanization usage could either be positive or negative.

Distance: Distance of farm from the nearest mechanization center/service. The shorter the distance of the farm from the mechanization center, the higher the chance of the farm deploying the service on his farm and vice versa. 
Mechanization index $\left(\mathbf{I}_{m}\right)$ : This variable measures the extent to which farmers are using machinery available both at the activity level and at the farm level. It is hypothesized that higher mechanization intensity index has a positive relationship with rice paddy output and productivity ${ }^{[25]}$. As farmers increase usage of machinery more work is done in shorter period, greater efficiency is achieved in terms of output and cost and hence increased income ${ }^{[26]}$.

Distance of farm from mechanization service center: The longer the distance from mechanization service the less motivated the farmer to employ its service in his activities.

Access to institutional credit: This is measured as a dummy variable. It takes 1 for a farmer who was able to access credit and 0 otherwise. It is hypothesized that access to credit by the farmer will enable him/her to intensify mechanization.

Age of farmer: This variable is measured in years. Older farmer employ much more experience in their production activity which may reflect in increased intensity of mechanization ${ }^{[19]}$.

Formal education of farmer: This variable correlates positively to higher intensity of mechanization because years in school may have exposed the farmer to modernized agricultural technology.

Farming experience: Longer years of farming could lead to employing labour saving technology hence, may have a positive influence on intensity of farm machinery use.

Rice income: This variable measures total income from rice output (GHS). Higher incomes from the farm will motivate the farmer to invest in labour saving technologies for his/her activities, and this will increase intensity of mechanization.

Nonfarm income: This variable represents the amount of income received by the farmer from sources other than farming (GHS). Non-farm income contributes positively to acquisition of farm machinery or hiring of machinery service to perform farm activities ${ }^{[27]}$. It is hypothesized that non-farm income will contribute positively to mechanization intensity.

Labour: This variable is expenditure on labour used (GHS). Amount of labour available and expenditure on labour could influence intensity of mechanization. An increase in intensity of mechanization is associated with increase in labour expenditure due to larger areas cultivated and employment of skilled labour to operate the machinery ${ }^{[23]}$. Intensification of mechanization increases hired labour expenditure but decreases amount of family labour used ${ }^{[24]}$.

Ownership of land: Farmers who rent land for rice farming may not be motivated to invest in capital machinery but farmers owning title deeds to lands may invest more in machinery to use on the farm, as long as they wish to farm. This will have a positive influence on mechanization intensity. 


\section{RESULTS AND DISCUSSIONS}

\section{DEMOGRAPHIC CHARACTERISTICS OF RESPONDENTS GENDER OF RESPONDENTS}

Gender distribution of respondents across the study area is presented in Figure 1. The result indicates that 18.1 percent of the respondents are female from the ShaiOsudoku District while 7.5 percent are female respondents from the Ketu North District. Fifty one percent of the male respondents are from the Shai-Osudoku District while 23.1 percent of male respondents are from the Ketu North District. In total 25.6 percent of the respondents are female while 74.4 percent of the respondents are males. These suggest that rice farming in the study area is male dominated in both districts. Female participation in rice production is higher in the Shai-Osudoku compared to the Ketu North District. The table also indicates that 69.4 percent of respondents are from the Shai-Osudoku District while 30.6 percent of respondents are from the Ketu North District. This could be attributed to the fact that size of developed land for rice production as well as number of farmers in rice production is higher in the Asutsuare area in the Shai-Osudoku District as compared to that of Weta area in the Ketu North District ${ }^{[7]}$.

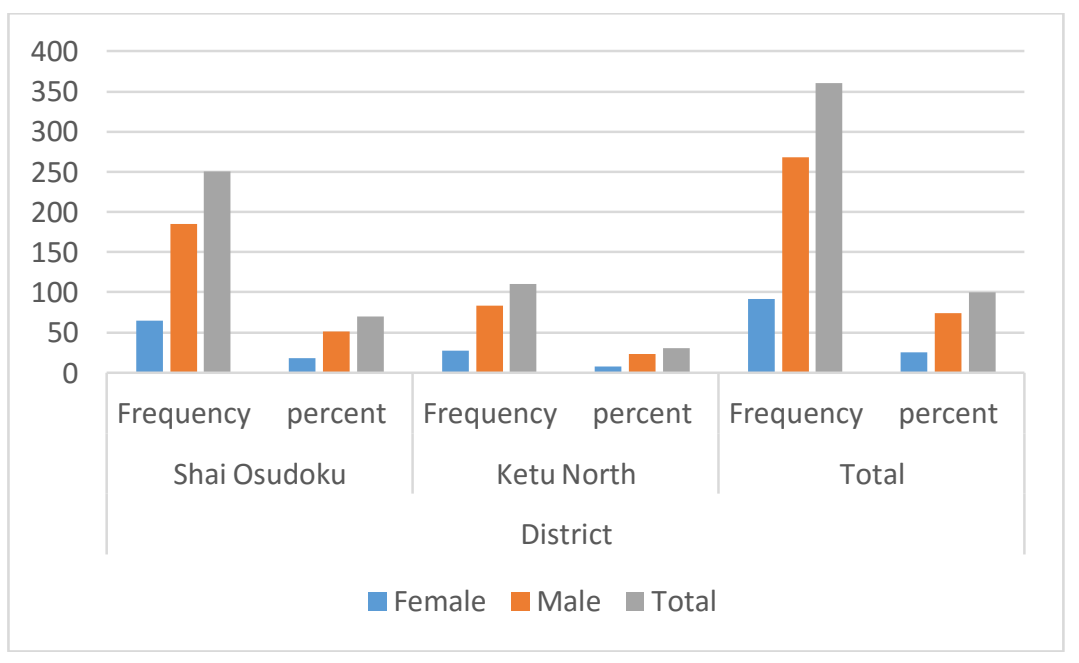

Figure 1: Gender of Respondents

Age of respondents, years of experience in rice farming, household size, numbers of contacts with extension agent are presented in Table 1. The age distribution shows that the minimum age of respondents was 20 years, the maximum age was 70 years and the mean age was 40 years. These indicate that farmers of all ages are involved in rice farming.

The minimum year of experience of respondents was 0 , the maximum is was 33 years and the mean year of experience was 10 years. These suggest that some farmers have been consistent in rice production for more than three decades while new entrants are venturing into the business of rice production. About 76.8 percent of respondents indicated that their main reason for entering rice farming is cash income. This suggests that experienced farmers are comfortable with the income levels from rice. This finding is reinforced by the fact that 61.1 percent of the respondents are engaged in rice farming as their sole occupation.

The minimum household size of respondents was 1 , the maximum was 18 , and the mean household size was 6 . The minimum contact with extension agent recorded was 0 , the maximum was 21 and mean was 1 . A further analysis shows that 72.8 
percent of respondents had no contact with extension agent throughout 2012 season of rice production. Majority of the remaining 37.2 came into contact with the extension agents because there was a government initiated mass pest control exercise against army worm outbreak particularly, in the Ketu North District.

\section{YEARS OF FORMAL EDUCATION}

Years of formal education by respondents indicates 0 years for minimum, 20 years for maximum and 9 for mean years of formal education. These imply that averagely, rice farmers spent 9 years to educate themselves formally, and this is equivalent to the number of years spent in basic education. The largest proportion of respondents, representing about 58 percent attained the Middle School Leaving Certificate (MSLC) or the Junior Secondary School level of education. This level of education is the basic level; it is compulsory and regulated by government policy, Free Compulsory Universal Basic Education (FCUBE).

Table 1: Summary statistics of other socio-economic variables

\begin{tabular}{lccccc}
\hline Statistics & $\begin{array}{l}\text { Age of } \\
\text { respondent }\end{array}$ & $\begin{array}{l}\text { Years of } \\
\text { formal } \\
\text { education }\end{array}$ & $\begin{array}{l}\text { Experience } \\
\text { (years) }\end{array}$ & $\begin{array}{l}\text { Household } \\
\text { size }\end{array}$ & $\begin{array}{l}\text { No. of contacts } \\
\text { with extension } \\
\text { agent }\end{array}$ \\
\hline Minimum & 20.00 & 0.00 & 0.00 & 1.00 & 0.00 \\
Maximum & 70.00 & 20.00 & 33.00 & 18.00 & 21.00 \\
Mean & 40.12 & 9.15 & 9.89 & 5.50 & 0.92 \\
Std. Error of & 0.57 & 0.20 & 0.38 & 0.16 & 0.13 \\
Mean & 10.78 & 3.94 & 7.07 & 3.01 & 2.53 \\
Std. Deviation & & & & & \\
\hline
\end{tabular}

Source: Authors' computation from field data 2012

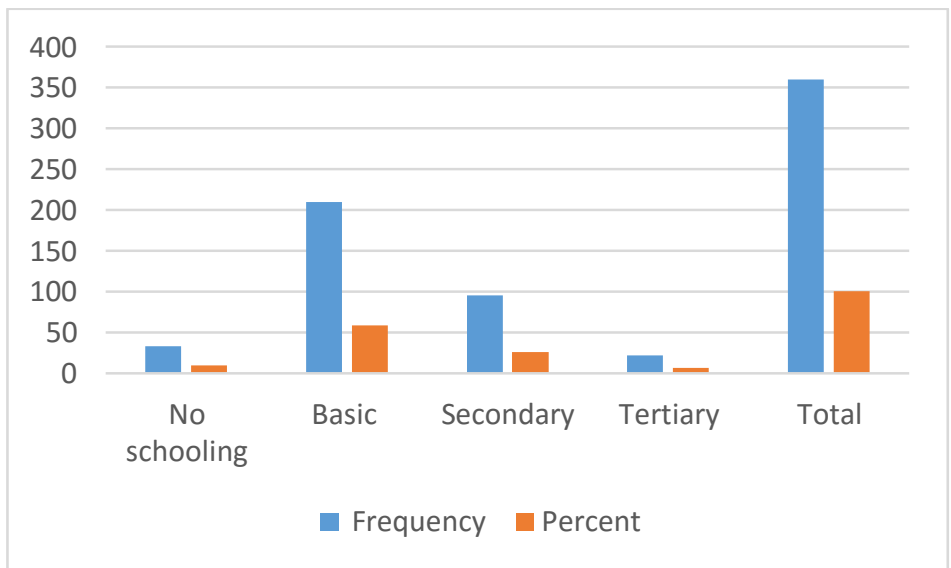

Figure 2: Level of education of respondents

\section{TOTAL LAND SIZE AND OWNERSHIP}

The minimum land size cultivated by respondents was 0.20 ha, the maximum land size was $12.00 \mathrm{ha}$, and the mean land size was 1.04 ha. The respondents cultivated a total of 399.17 ha, 225.6 ha representing 52.62 percent of cultivated land were owned by respondents and 173.57 ha representing 43.48 percent of cultivated land were rented (Table 2).

Land ownership here means either the farmer inherited the land in the case of undeveloped land, or the farmer was allocated the piece of land by the Irrigation Development Authority, or the piece of land was allocated to a close relative of the farmer (say mother, father, and grandparents) and hence the farmer does not pay any amount for usage of the land. The mean land size owned by respondents was 0.8 ha, 
the minimum size owned was 0.2 ha and the maximum size of land owned was 2.4 ha.

The minimum size of rented land cultivated by farmers was 0.2 ha, the mean was 1.2 ha and the maximum was 5.2 ha. The average rent price of a hectare of land per season was GHS 307.45. The minimum hiring price per hectare per season was GHS100.00 and the maximum was GHS 750.00 (Table 2) ${ }^{2}$.

\section{IMPROVED SEED EXPENDITURE}

The major varieties of seeds sown by rice farmers in the study area include the Marshall, Jasmine and Get three (3). These are improved varieties with aromatic flavor and desirable consumer characteristics ${ }^{[28]}$. About 98 percent of respondents grow these varieties and the remaining 2 percent of respondents grow the traditional variety called Torse. In general, the mean seed rate used by the farmers in the study area was $119.25 \mathrm{~kg}$ per hectare with an expenditure of GHS 122.69. The minimum seed rate was $35 \mathrm{~kg}$ per hectare with an expenditure of GHS 21.88 while the maximum seed rate was $240 \mathrm{~kg}$ per hectare with an expenditure of GHS 300.00. More specifically, the mean seed rate for farmers who broadcasted their seeds was $142.8 \mathrm{~kg}$ per hectare (this rate is higher than the recommended $100 \mathrm{~kg}$ per hectare) while the mean seed rate for those farmers who transplanted was $89.13 \mathrm{~kg}$ per hectare (this is higher than the recommended $75 \mathrm{~kg}$ per hectare (Table 2). This suggests that broadcasting of seeds in rice production increases seed rate while transplanting decreases seed rate. Broadcasting seeds does not take into account row planting, specific planting distance and seed per hill as transplanting does. Broadcasting could be a contributing factor to excessive seed rate because 55.8 percent of the farmers broadcasted their seed while 44 percent transplanted their seed.

\section{LABOUR AND LABOUR EXPENDITURE}

The minimum labour requirement per hectare of rice cultivated was 63 man-days with a minimum per ha labour expenditure of GHS 281.26; the maximum labour required per hectare was 407.50 man-days with a maximum labour per ha expenditure of GHS 3645.10 per ha, and the mean labour required per ha was 172 man-days with a mean per ha labour expenditure of GHS 1470.24 (Table 2). Labour requirement vary widely across respondents. It is based on specific growth stage of the rice plant, demand made by the soil and crop conditions, and whether machinery is available to substitute for labour on a particular plot.

\section{EXPENDITURE ON MECHANIZATION}

The expenditure on mechanization per hectare of rice farm depends on the type and number of agronomic practices mechanized as well as availability of the machinery. The most common expenditure on mechanization of rice production was expenditure on land tillage. The minimum expenditure on mechanization recorded by respondents was GHS 0.00, the maximum was GHS 1276.00, and the mean was GHS 666.89 (Table 2). This suggests that those who recorded GHS 0.00 expenditure on mechanization did not mechanize any of the agronomic activities in their production cycle during the period under study.

${ }^{1} 1 \mathrm{GHS}=0.52$ USD when the data was collected in December 2012 .

\section{EXPENDITURE ON FERTILIZER}

Application of fertilizer in rice production is shown to be extensive in the study area. The type of fertilizer ranges from compound fertilizers for example, NPK and nitrogen based fertilizers such as urea and ammonia in their various forms, for example, granule, liquid and crystalline. The minimum fertilizer expenditure per 
hectare was GHS 118.3, the maximum expenditure was GHS 1019.06 and the mean was GHS 501.13 (Table 2). These values depended on whether the farmers had access to government subsidized fertilizer or whether the farmers purchased the fertilizer in the open market.

The mean rate of fertilizer application for NPK was $350 \mathrm{~kg}$ per hectare, $125 \mathrm{~kg}$ per hectare for urea and $125 \mathrm{~kg}$ per hectare for ammonia. These were applied in granulated form and complimented with average of 1 liter per hectare of folia application of different combinations of plant nutrients. The minimum expenditure on fertilizer applied in the study area was GHS 118.13 per hectare; the maximum expenditure was GHS 1019.06 per hectare and the mean expenditure was GHS 501.13 per hectare (Table 2). The gap between the different application rates could be due to the farmer's perceived nutrient status of the soil and also financial capabilities to purchase the required quantity of fertilizer for rice production.

\section{AGROCHEMICAL EXPENDITURE}

Agrochemical usage for rice production in the area is shown to be extensive. These chemicals are mostly weedicides, insecticide, nematicides and rodenticides. The weedicides include broad spectrum chemicals like glyphosate, selective grass killers and selective broad leave killers. The applications of these chemicals start from land preparation till the set of the inflorescence of the rice plant on the field. Some applications are planned and done at specific growth stage of the rice but others are also done as to when the need arises.

These agrochemicals come in various forms (liquid, powder, crystals) and various packages so their application rate can best be expressed in terms of expenditure per hectare. The mean expenditure of weedicide used in the study area was GHS138.83 per hectare and the mean expenditure of the other pesticides used was GHS 25.75. In total, the minimum amount of expenditure on agrochemicals in the study area was GHS 6.17 per hectare, the maximum expenditure on agrochemicals was GHS 448.42 per hectare and the mean expenditure on agrochemical was GHS 134.18 per hectare (Table 2).

\section{AVERAGE DISTANCE TO A MACHINE}

Some farms are located $13 \mathrm{~km}$ from human habitations while other farms are located within $0.7 \mathrm{~km}$ of human settlements. Some mechanization service providers, for example tillage service providers live within the rice growing communities, however, some services, for example reaping and threshing are provided by machinery shops further away from the farming communities. For all of activities mechanized on the rice farms, farmers were able to access available machinery within an average of $5.42 \mathrm{~km}$ (Table 2).

\section{OUTPUT VALUE}

The mean physical output of rice paddy was 4.59 metric tonnes per ha. The respondents recorded a minimum physical paddy output of 1.01 metric tonnes per hectare and the maximum output recorded was 9.9 metric tonnes per hectare. The mean yield of rice paddy in the study area falls below the findings of research on the Kpong Irrigation Scheme (6-7 metric tonnes per hectare) ${ }^{[28]}$. This implies that the mean paddy output is declining. The physical paddy output is measured in $90 \mathrm{~kg}$ unit bags, however, an adjustments of $6 \mathrm{~kg}$ per bag is made for the husk contained. The physical output of paddy was valued at the average selling price of 2012 major season, GHS 0.95 per $\mathrm{kg}$. The results indicated a minimum output value of GHS 900.00 per hectare, a maximum output value of GHS 8800.00 and a mean output value of GHS 4088.22. The variations in output value could be due to the combination of factors that influence the physical output of rice paddy. 
Table 2: Summary statistics of farm level variables

\begin{tabular}{|c|c|c|c|c|c|c|c|c|c|c|}
\hline Statistics & $\begin{array}{l}\text { Total } \\
\text { land } \\
\text { size } \\
\text { (ha) }\end{array}$ & $\begin{array}{l}\text { Land hiring } \\
\text { price/hectare } \\
\text { /season } \\
(\mathrm{GH} \phi)\end{array}$ & $\begin{array}{l}\text { Seed } \\
\text { rate/ha } \\
(\mathrm{kg})\end{array}$ & $\begin{array}{c}\text { Seed } \\
\text { expenditu } \\
\text { re/ha } \\
(\mathrm{GH} \phi)\end{array}$ & $\begin{array}{l}\text { Labour } \\
\text { expendit } \\
\text { ure/ha } \\
(\mathrm{GH} \phi)\end{array}$ & $\begin{array}{l}\text { Mech. } \\
\text { expenditu } \\
\text { re/ha } \\
(\mathrm{GH} \phi)\end{array}$ & $\begin{array}{c}\text { Credit } \\
\text { received/ } \\
\text { ha }(\mathrm{GH} \phi)\end{array}$ & $\begin{array}{c}\text { Fertilizer } \\
\text { expenditure } \\
\text { /ha }(\mathrm{GH} \phi)\end{array}$ & $\begin{array}{c}\text { Agrochemical } \\
\text { expenditure/ha } \\
(\mathrm{GH} \phi)\end{array}$ & $\begin{array}{c}\text { Average } \\
\text { distance to } \\
\text { a machine } \\
(\mathrm{km})\end{array}$ \\
\hline Mean & 1.04 & 307.45 & 119.25 & 122.69 & 1470.24 & 666.89 & 1182.59 & 501.13 & 134.18 & 5.42 \\
\hline $\begin{array}{l}\text { Std. Error } \\
\text { of Mean }\end{array}$ & 0.04 & 11.01 & 2.48 & 2.70 & 34.07 & 11.27 & 63.53 & 7.94 & 3.49 & 0.15 \\
\hline $\begin{array}{l}\text { Standard } \\
\text { Deviation }\end{array}$ & 0.69 & 125.07 & 47.13 & 50.86 & 641.92 & 213.92 & 845.28 & 148.61 & 65.43 & 3.00 \\
\hline Minimum & 0.20 & 100.00 & 35.00 & 21.88 & 281.67 & 0.00 & 50.00 & 118.13 & 6.17 & 0.67 \\
\hline Maximum & 12 & 750.00 & 240.00 & 300.00 & 3645.10 & 1276.00 & 4000.00 & 1019.06 & 448.42 & 13.33 \\
\hline
\end{tabular}




\section{ACCESS TO INSTITUTIONAL CREDIT}

It was observed that about 49.4 percent of the respondents received credit from various sources for their rice production activities in the 2012 major season (Table 3). The minimum amount of credit received per hectare was GHS 50.00, the maximum amount of credit received per hectare was GHS 4000.00, and the mean amount of credit received per hectare was GHS 1182.59 (Table 2).

The sources of credit are also presented in Table 3. The most important source of credit for the rice farmers in the study area was produce buyers (trade credit). Twenty one percent of total respondents received credit from produce buyers, 9.2 percent from money lenders, 12 percent of respondents received their credit from formal financial institutions, the banks. This occurrence could be due to that fact that the produce buyers know the farmers based on personal relationship and trust. Some produce buyers and money lenders live in the same community with the farmers, hence; they may not demand stringent collaterals that formal credit institutions require from farmers. This enables the produce buyers to pre- finance the production activities of the farmers. Also, bureaucratic procedures and delays in credit disbursement that characterize credit request from formal credit institutions are eliminated when money lenders and produce buyers offer credit to farmers.

A detailed breakdown of the timeliness of amount of credit received in relation to the source revealed that 75 percent of farmers who had their source of credit supply from produce buyers indicated that the credit was received on time and it served the purpose for which it was intended, while 25 percent of those who received credit from produce buyers said the credit was not received on time. Also, for those who received credit from money lenders, 63 percent admitted that the credit was received on time but 37 percent of those who had credit from money lenders admitted that credit was not received on time. On the other hand, 39 percent of those who received credit from Rural Banks said the credit was received on time and 61 percent said the credit was not received on time. With regard to Agricultural Development Bank, 42.8 percent of respondents admitted receiving the credit on time and 57.2 percent of respondent admitted they did not receive the credit on time. With regard to other commercial banks, 20 percent of the respondents said they accessed the credit in time while 80 percent mentioned that the credit was not given to them on time. Also, about $83 \%$ of the farmers who received input credit from individual input dealers revealed that the credit was received on time.

Table 3: Access to credit and timeliness of delivery

\begin{tabular}{lcccc}
\hline Sources of credit & \multicolumn{2}{c}{ Access to credit } & \multicolumn{2}{c}{ Timeliness of delivery } \\
& Frequency & Percent & Frequency & Percent \\
\hline Rural Bank & 23 & 6.40 & 9 & 39.13 \\
Agricultural Development Bank & 14 & 3.90 & 6 & 42.80 \\
Other Commercial Banks & 5 & 1.40 & 1 & 20.00 \\
Produce buyer (pre-finance) & 76 & 21.10 & 57 & 75.00 \\
Relative/Friend & 19 & 5.30 & 8 & 42.44 \\
Individual input dealer & 6 & 1.70 & 5 & 83.33 \\
Money Lender & 33 & 9.20 & 21 & 63.00 \\
Susu or credit union & 1 & .30 & 1 & 100.00 \\
Work Place & 1 & .30 & 1 & 100.00 \\
Sub Total (credit access) & 178 & 49.40 & 109 & 61.23 \\
No access to credit & 182 & 50.60 & & \\
Total & 360 & 100.0 & & \\
\hline Source: Aunnnyyn
\end{tabular}

Source: Authors' computation from field data 2012 


\section{SOURCES OF MECHANIZATION SERVICES ACCESSED BY RICE FARMERS IN SOUTHERN GHANA}

The results revealed that private individuals were the main source of mechanization service provision for most activities on the rice farm; $85.6 \%$ in the case of tillage; $34.5 \%$ in the case of reaping, $39.1 \%$ in the case of threshing, $84.5 \%$ in the case of transportation and $65.2 \%$ in the case of winnowing. With regards to irrigation, government was the main source of service provision, $81.9 \%$ of farmers had access to irrigation from government irrigated land (Table 4).

Table 4: Sources of machinery for mechanization activities on rice farms

\begin{tabular}{lllllll}
\hline & $\begin{array}{l}\text { Tillage } \\
(\%)\end{array}$ & $\begin{array}{l}\text { Irrigation } \\
(\%)\end{array}$ & $\begin{array}{l}\text { Reaping } \\
(\%)\end{array}$ & $\begin{array}{l}\text { Threshing } \\
(\%)\end{array}$ & $\begin{array}{l}\text { Transportation } \\
(\%)\end{array}$ & $\begin{array}{l}\text { Winnowing } \\
(\%)\end{array}$ \\
\hline $\begin{array}{l}\text { Unmotorized } \\
\text { Sources of mech. }\end{array}$ & 1.4 & 17.8 & 62.5 & 58.1 & 5.8 & 30.6 \\
$\begin{array}{l}\text { Self-Ownership } \\
\text { Private Individual }\end{array}$ & 7.7 & 0.3 & 0.2 & 0.3 & 5.8 & 4.2 \\
Gov't Mech. Centre & 5.3 & 81.9 & 2.8 & 2.5 & 3.9 & 65.2 \\
Total mech. & 88.6 & 82.2 & 37.5 & 41.9 & 94.2 & 0 \\
Total & $\mathbf{1 0 0}$ & $\mathbf{1 0 0}$ & $\mathbf{1 0 0}$ & $\mathbf{1 0 0}$ & $\mathbf{1 0 0}$ & 69.4 \\
\hline
\end{tabular}

Source: Authors' computation from field data 2012

\section{LEVEL OF MECHANIZATION ACCESSED BY FARMERS IN THE PRODUCTION CYCLE}

Twenty six percent of respondents indicated that they mechanized 50 percent or more of the activities on the rice farm while about 74 percent of respondents were not able to mechanize half of the activities on the rice farm.

Eleven activities or operations in the rice paddy production process required mechanization. The number of activities mechanized indicates the operations for which motorised equipment was used. The level of mechanization achieved indicates the proportion of activities mechanized.

The minimum number of activities mechanized was 1 (one); with a corresponding level of mechanization achieved being $9.0 \%$. About $4.4 \%$ of farmers achieved the minimum level of mechanization. All the respondents were able to access machinery to mechanize at least one activity in the paddy production process.

The maximum number of activities mechanized was six (6), with a corresponding level of mechanization being 55\%. About $26.4 \%$ of respondents achieved 55\% mechanization in the rice production process. A higher proportion of respondents $(47.2 \%)$ mechanized four activities in the

paddy production process representing $36.0 \%$ level of mechanization. It appeared that this level was considerably low to cause appreciable level of increased productivity (Table 5). It seems that the agricultural machinery imported by the government of Ghana are not appropriate and affordable for intensive use by the smallholder farmers, and public sector machinery hire services are likely to be unreliable and not economical ${ }^{[16,17]}$. 
Table 5: Level of mechanization accessed by farmers

\begin{tabular}{|c|c|c|c|}
\hline Number of activities mechanized & $\begin{array}{l}\text { Level of mechanization } \\
\text { achieved (\%) }\end{array}$ & Frequency & Percent \\
\hline 1.00 & 9.0 & 16 & 4.4 \\
\hline 2.00 & 18.0 & 25 & 6.9 \\
\hline 3.00 & 27.0 & 28 & 7.8 \\
\hline 4.00 & 36.0 & 170 & 47.2 \\
\hline 5.00 & 45.0 & 26 & 7.2 \\
\hline 6.00 & 55.0 & 95 & 26.4 \\
\hline $7-11$ & 0.0 & 0 & 0 \\
\hline Total & & 360 & 100.0 \\
\hline
\end{tabular}

Source: Authors' computation from field data 2012

\section{DETERMINANTS OF ACCESS AND INTENSITY OF MECHANIZATION}

The empirical results of the double huddle model estimates are presented in Table 6 . The results revealed that size of land cultivated is significant at $1 \%$ and positively influenced access to mechanization. This re-affirms the findings of ${ }^{[19]}$ which suggest that large farms are more efficient and as a result were more able to access mechanization services than smaller farms. The coefficient of credit access is positive and highly significant at $1 \%$. This implies that access to credit facility enhanced a farmer's access to mechanization. This is due to the fact that access to credit enhances the farmer's purchasing power to enable the farmer purchase farm machinery which is capital intensive ${ }^{[8,14]}$. Alternatively, it will make it relatively easier for a farmer to hire the machinery service available to undertake farm operations. Availability of machinery service centre is positive and highly significant at $1 \%$. This means that setting mechanization service centres within the vicinity of the farmers is critical in enhancing their access to mechanised rice farming. Improved seed expenditure is highly significant at $1 \%$ but negative. This could be attributed to the fact that farmers sowed seed quantities above the recommended seed rate. Excessive seed rate increases plant density per hectare, reduced aeration and reduced rice paddy output per hectare. This might have resulted in relatively lower revenues thereby making it difficult for the farmer to access mechanized services. Labour expenditure is highly significant at $1 \%$ and positive. This could be attributed to the fact that skilled labour is hired to operate the farm machinery. Relatively, higher wages are paid for skilled labour usage; hence, labour expenditure complements access to mechanization. Agrochemical expenditure is significant at $1 \%$ and positively related to access to mechanization. This is because mechanization is not considered as a sole panacea but rather an input that needs to be complemented with agrochemical usage. Age of the farmer is significant at $10 \%$ but negative. This contradicts the findings of ${ }^{[14]}$ which suggest that older farmers are more likely to intensify machinery usage because they might have saved enough money over the years to enable them purchase needed machines for farming. Increase in age does not necessarily guarantee availability of resources that will enable the farmer to access machinery for farming. However, as farmers increase in age, they turn to have more confidence in the ability of using traditional methods of production ${ }^{[20]}$. Interestingly, the square of age is significant at $5 \%$ and positive. This means as age increases to some point, it translates to influence access to mechanization positively.

Gender is highly significant at $1 \%$ and positive. It means that being a male farmer increased access to mechanization. This situation could be as a result of machinery operation being dominated by male because skills set used in operating the 
machinery require some physical strength possessed by males. The farm equipment's are thus operated by males, some of them being farmers, hence, promoting access of the operator's farm to mechanization. District location of respondents is significant at $1 \%$ and negative. This implies that when a farmer is located in the Shai-Osudoku district, the farmers' access to mechanization decreases.

Distance from farm to the nearest mechanization centre was significant at $1 \%$ and positive. This indicates that as farmers get further away from the mechanization service centre, they turn to intensify the use of mechanization. This is contrary to expectation. The 'mechanization centres' in the areas under study were situated within human settlements, either on the office premises of the project sites or in homes of private individuals. Farms with longer distances to mechanization centre means that they are located in more remote sites and far from human habitation. It is intuitive that farms situated further away from the mechanization centres have greater needs of mechanization, for example, a farm that is $15 \mathrm{~km}$ away from the mechanization centre have greater need to use tractor to transport paddy from the field. This placed a greater demand on the farmers whose farms are distant to employ mechanized service to undertake activities on the farm, hence, increased intensity of mechanization for remote farms. Land ownership was significant at $10 \%$ but a negative determinant of mechanization intensity. The mean total owned land ( $0.82 \mathrm{ha}$ ) cultivated is smaller than the total average land size cultivated (1.04 ha) by farmers in the study area in 2012 major season. This could account for land ownership being a negative determinant of mechanization because larger land sizes have increased access to mechanization thereby leading to increased intensity of machinery usage ${ }^{[8,14]}$.

Income from rice was significant at $5 \%$ and positive in determining the intensity of mechanization on rice farms. A cedi increase in the income from rice output will cause mechanization intensity to increase and vice versa. This is because as income from rice production increases at a constant cost, higher profits would be made by farmers and this could be saved. This savings could be used to acquire capital intensive machinery or hire machinery services to undertake activities on the rice farms. This implies that for farmers to intensify mechanization on the rice farms, rice production must first be profitable.

Non-Farm Income was positive and significant at 5\% in determining mechanization intensity. This is due to the fact that increase in non-farm income increases amount of money available for the farmer to invest in farm machinery acquisition or hire, to undertake mechanization activities on the rice farm. Non-farm income therefore, is an indirect determinant of productivity by means of enhancing farm machinery acquisition ${ }^{[18]}$. Experience was significant at $10 \%$ and positively related to mechanization intensity. Long years of rice farming may have resulted in accumulated savings based on the assumption that rice farming business is profitable. This accumulated savings could be used to purchase or hire farm machinery and labour saving technologies. Also, farmers may have gained more efficient ways of combining various technologies on the farm over the years. Household size was significant at $5 \%$ but negative. This is intuitive because, larger household size possibly makes available some family labour to undertake activities on the farm. Since mechanization is a labour replacing activity, larger family means abundant labour; therefore less activities for machinery to mechanize, hence, decreased intensity of mechanization. 
Table 6: Craggits' double hurdle model estimates of determinants of access and intensity of mechanization on rice farms

\begin{tabular}{|c|c|c|c|}
\hline Variable & Coefficient & Standard Error & $p$-value \\
\hline \multicolumn{4}{|l|}{$F M$} \\
\hline Land & $23.0964 * * *$ & 1.0525 & 0.000 \\
\hline Cred & $11.6297 * * *$ & .4449 & 0.000 \\
\hline Memb & -1.271443 & 1.1621 & 0.274 \\
\hline AMS & $47.0526 * * *$ & 1.2314 & 0.000 \\
\hline Seed & $-.0817 * * *$ & .0020 & 0.000 \\
\hline $\mathrm{Lab}$ & $.0070 * * *$ & .0007 & 0.000 \\
\hline Agrochem & $.0423 * * *$ & .0029 & 0.000 \\
\hline Age & $-.3124 *$ & .1770 & 0.078 \\
\hline Age2 & $.0053 * *$ & .0021 & 0.015 \\
\hline Gender & $9.1289 * * *$ & .4802 & 0.000 \\
\hline District & $-1.4107 * * *$ & .2553 & 0.000 \\
\hline Constant & -15.2046 & 3.4715 & 0.000 \\
\hline \multicolumn{4}{|l|}{$I_{m}$} \\
\hline Distance & $.0104 * * *$ & .0040 & 0.009 \\
\hline Land & .0253 & .0235 & 0.280 \\
\hline Land ownership & $-.0512 *$ & .0304 & 0.092 \\
\hline Rice Income & $.0000 * *$ & .0000 & 0.011 \\
\hline NF Income & $.0000 * *$ & .0000 & 0.018 \\
\hline $\mathrm{Lab}$ & .0000 & .0000 & 0.901 \\
\hline Cred amt. & .0000 & .0000 & 0.215 \\
\hline Ext & .0037 & .0032 & 0.244 \\
\hline Age & .0141 & .0094 & 0.131 \\
\hline $\mathrm{Age}^{2}$ & -.0001 & .0001 & 0.180 \\
\hline Gender & -.0038 & .0204 & 0.850 \\
\hline Exp. & $.0040 *$ & .0022 & 0.070 \\
\hline Household & $-.0129 * *$ & .0053 & 0.015 \\
\hline Constant & -.3862 & .1945 & 0.047 \\
\hline \multicolumn{4}{|l|}{ Sigma } \\
\hline Constant & .1400875 & .0144 & 0.000 \\
\hline Observations (N) & 360 & & \\
\hline Prob $>$ chi Squared & 0.000 & & \\
\hline Log pseudolikelihood Robust & 410.97 & & \\
\hline Wald chi Squared & 3452 & & \\
\hline
\end{tabular}

\section{CONCLUSIONS}

The survey results revealed that the major source of machinery service provision was private service providers for all activities that used mechanization except in the case of irrigation where government is the major service provider. This implies that rice farmers rely on private service providers for their mechanization service on the farm because mechanization services from government is either unavailable or inadequate. However, these private service providers are not necessarily those supported under public private partnerships. Furthermore, survey results revealed that government is the dominant service provider for irrigation on the rice farms. This means that prospective rice farmers who are interested in cultivating irrigated rice will rely on government for infrastructural support and service. Out of a total of eleven activities on the rice farms, a maximum of six were mechanised by farmers. Farmers who had access to mechanization used motorized equipment to undertake at least one of the following activities; tillage, irrigation, reaping, threshing, transportation and winnowing. Activities such as planting activities, weed control 
spraying, insect control spraying, fertiliser application and drying have not been mechanised due to the fact that machinery for mechanising these activities were not available to farmers. The activity most mechanized was tillage ( $88.6 \%$ of farmers) and the least mechanized activity was reaping (37.5\% of farmers). Majority of the farmers have been able to mechanize at least one activity. The modal number of activities mechanized by farmers is four ( $47.2 \%$ of farmers) with a corresponding level of mechanization of $36.0 \%$. About $26.4 \%$ of farmers have been able to mechanize half or more of the activities on the rice farm with a corresponding $55.0 \%$ level of mechanization. About $73.6 \%$ of rice farmers are operating at a mechanization level of $45 \%$ or less. The results of tier one of the double huddle model revealed that total size of land cultivated, access to credit, availability of farm machinery in the community, labour expenditure, agrochemical expenditure, square of age and gender were positive determinants of access to mechanization. On the other hand, seed expenditure, age and district locations of farmers were negative determinants of access to mechanization. District location had the greatest negative influence on access to mechanization followed by age and seed expenditure. The tier two of the double huddle model revealed that distance from farm to the nearest mechanization centre, rice income; non-farm income and experience positively determined intensity of mechanization. Land ownership and household size negatively determined intensity of mechanization. These results have implications for capacity building and government support for rice farmers in southern Ghana.

\section{REFERENCES}

1. Government of Ghana. Growth and Poverty Reduction Strategy (GPRS II). Assembly Press, Accra. 2006.

2. Government of Ghana. Ghana Shared Growth and Development Agenda. Medium-Term Development Plan. Assembly Press, Accra. 2010.

3. Ministry of Food and Agriculture. Food and Agricultural Sub-Sector Development Policy. SRID,

Accra, Ghana. 2007.

4. Reid JF. Impact of Mechanization on Agriculture. In Alleyne, A, and Baroni, M. edition, The Bridge Linking Engineering and Society. 2011; 41(3), 22-29. National Academy of Engineering Constitution Avenue N.W; Washington D.C.

5. Ministry of Food and Agriculture. Medium Term Agriculture Sector Investment Plan (METASIP). 2011 - 2015, SRID. Accra, Ghana. 2010.

6. Regassa EN, Horowitz L, Kolavalli S, Kranjac-Berisavljevic G, Dawuni BN, Barry B, Giordano M. Typology of Irrigation Systems in Ghana, IWMI Working Paper 142, International Water Management Institute. 2010.

7. Ministry of Food and Agriculture. Agriculture in Ghana. Facts and Figures 2010, SRID, Accra, Ghana. 2011.

8. Binswanger HP. Agricultural Mechanization A Comparative Historical Perspective, University of Oxford, UK, 1978.

9. Clarke LJ. Strategies for Agricultural Mechanization Development the Roles of the Private Sector and the Government, Agricultural Engineering Branch, Agricultural Support Systems Division FAO, Rome, Italy, 2000.

10. Food and Agriculture Organization \& UNIDO. Agricultural mechanization in Africa. Time for action: planning investment for enhanced agricultural productivity. Report of an expert group meeting jointly held by FAO and UNIDO in Vienna on 29-30 November 2007. Rome, FAO, 2008.

11. Sims BG, Kienzle J. Farm power and mechanization for small farms in sub Saharan Africa, Agricultural and Food Engineering Technical Report. Food and Agriculture Organisation of the United Nations, Rome. 2006.

12. Pingali P, Bigot Y, Binswanger, H. Agricultural mechanization and the Evolution of Farming Systems in Sub-Saharan Africa. Washington, DC: World Bank, 1987. 
13. Food and Agriculture Organization. Socio-economic Impact of Smallholder Irrigation Development in Zimbabwe: Case Studies of ten Irrigation Schemes, SAFR/AGLW/DOC/002 - Harare, FAO Sub-Regional Office for East and Southern Africa (SAFR), 2000.

14. Mrema CG, Baker D, Kahan D. Agricultural Mechanization in Sub- Saharan Africa: Time for a New Look. Rome: Food and Agriculture Organization of the United Nations, 2008.

15. Obi, A., Chisango F. Performance of Smallholder Agriculture under Limited Mechanization and the Fast Track Land Reform Program in Zimbabwe. International Food and Agribusiness Management Review. 2011; 14(4): 85-104.

16. Diao X, Cossar F, Houssou N, Kolavalli S. Mechanization in Ghana: Emerging demand, and the search for alternative supply models. Food Policy. 2014; 48: 168-181.

17. Sims BG, Kienzle J. Making Mechanization Accessible to Smallholder Farmers in SubSaharan Africa. Environments. 2016; 3(11): 1-18.

18. Ministry of Food and Agriculture. Medium Term Agriculture Sector Investment Plan (METASIP) 2011 - 2015, SRID, Accra. 2010.

19. Ghosh BK. Determinants of Farm Mechanization in Modern Agriculture: A Case Study of the Burdwan District of West Bengal. International Journal of Agricultural Research. 2010; 5(12):1107-1115.

20. Greene WH. Econometric Analysis, Fifth Edition. Pearson Education, Inc. Upper Saddle River, New Jersey, 2003. pp. 112-114.

21. Cragg J. Some statistical models for limited dependent variables with application to the demand for durable goods. Econometrica. 1971; 39: 829-44.

22. Olwande J, Mathenge M. Market Participation among Poor Rural Households in Kenya. Selected paper prepared for presentation at the International Association of Agricultural Economists (IAAE) Triennial Conference, Foz do Iguaçu, Brazil, 18-24 August, 2012.

23. Balishter GVK, Singh R. Impact of Mechanization on Employment and Farm Productivity. Productivity. 1991; 32(3): 484-489.

24. Verma SR. Impact of Agricultural Mechanization on Production, Productivity, Cropping Intensity, Income Generation and Employment of Labour: Status of Farm Mechanization in India. Punjab Agricultural University, Ludhiana, 2008. pp. 133-153.

25. Nandal DS, Rai KN. Impact of Farm Mechanization on Farm Productivity in Haryana. 1986.

26. National Council of Applied Economics Research. Impact of Mechanization in Agricultural on Employment. Report of National Council of Applied Economics Research, New Delhi. 1973.

27. Reardon T, Kelly V, Crawford E, Jayne T, Savadogo K, Clay D. Determinants of Farm Productivity in Africa: a Synthesis of Four Case Studies. Policy Synthesis for Cooperating USAID Offices and Country Missions. 1996.

28. Tinsley R. Increasing Rice Productivity for the Kpong Irrigation Project AkuseAsutsuare, Ghana. Farmer-to-Farmer Program, Consultant Report. ACDI/VOCA, Accra, 2009.

29. Foster AD, Rosenzweig MR. Are Indian Farms Too Small? Mechanization, Agency Costs and Farm Efficiency. Brown University. 2011.

30. Owombo PT, Akinola AA, Ayodele OO, Koyedole GF. Economic Impact of Agricultural Mechanization Adoption: Evidence from maize farmers in Ondo State Nigeria. Journal of Agricultural and Biodiversity Research, 2012; 1(2): 25-32. 